\title{
DMS Agar, a New Composite Tube Medium for Differentiation Within the Genus Salmonella
}

\author{
STEFAN I. BONEV \\ Laboratory for Zoonoses, Dargaven Ekarisage, Burgas, Bulgaria
}

\begin{abstract}
A new agar medium, DMS agar, which combines dulcitol and salicin fermentation with malonate utilization, is described for use in differentiating Salmonella subgenera.
\end{abstract}

In 1960 Kauffmann (6) suggested division of the genus Salmonella into two subgenera. Later he (7) further proposed the addition of members of the Arizona group to the genus Salmonella, as subgenus III. The typical reactions of these subgenera were reported $(1-3,8)$. In 1965 Kauffmann (9) listed the differential reactions for strains of what he termed subgenus IV. Table 1 shows the biochemical differences between the members of these subgenera, as they were listed by Kauffmann (10).

The use of all of these tests would be in agreement with the so-called "blunderbuss method" formulated by Steel (14) for identification of pure cultures, but it is not convenient for general use in daily practice. It is possible, however, to draw a line between these subgenera using some selected criteria (method of probabilities), such as their reactions in malonate, dulcitol, and salicin broths.

Since the malonate test was originally developed by Leifson (12), only two composite tube media are known which combine the principle of malonate utilization with other biochemical reactions. The formulation of the first medium which combines malonate utilization with the production of pyruvic acid from phenylalanine was given by Shaw and Clark (13). Recently Stroup (15) developed a medium which combines tests for lysine decarboxylase, malonate utilization, $\mathrm{H}_{2} \mathrm{~S}$ production, and dulcitol fermentation, for use at the triple sugar iron agar stage for the identification of Salmonella subgenera I to III.

Based on the principle of Kligler iron agar, which combines three tests in one tube, a new agar medium, DMS agar, which combines dulcitol and salicin fermentation with malonate utilization, has been developed.

Test strains. A total of 79 Salmonella stock cultures were employed as test strains in this study. Of these, 21 belonged to subgenus I (13 were dulcitol negative and 8 were dulcitol fermenters), 20 were Salmonella subgenus II strains, 26 belonged to the Arizona group (Sal- monella subgenus III), and 12 were Salmonella subgenus IV strains.

Taxonomy and nomenclature. The taxonomy and nomenclature used in this study are those proposed by Kauffmann (11).

Media. Dulcitol and salicin fermentation broths were prepared by the method of Ewing and Davis (4). To test the malonate utilization, modified malonate broth (Difco 0569) was used.

The combined DMS agar has the following composition (grams per liter): yeast extract (BI27) (Difco), 1.0; $\mathrm{K}_{2} \mathrm{HPO}_{4}, 0.6 ; \mathrm{KH}_{2} \mathrm{PO}_{4}, 0.4$; ammonium sulfate, $2.0 ; \mathrm{NaCl}, 2.0$; sodium malonate, 3.0; dulcitol, 1.0; salicin, 10.0; bromothymol blue solution $(1: 500), 25.0 \mathrm{ml}$; agar (Difco), 8.0; distilled water, $1,000.0 \mathrm{ml}$; $\mathrm{pH} 6.7$.

Suspend the ingredients in cool distilled water and bring to a boil with constant shaking to dissolve ingredients and prevent the agar from burning. Distribute $6.0-\mathrm{ml}$ amounts in test tubes ( 12 by $120 \mathrm{~mm}$ ) stoppered with cotton plugs. Sterilize by autoclaving for $15 \mathrm{~min}$ at 121 C. Allow the medium in the tubes to solidify in a slanted position, making the ratio of the slant to the butt about 1:1.

Inoculation. Dulcitol and salicin fermentation broths and malonate broth were inoculated lightly by a young broth culture. DMS agar was inoculated by stabbing the butt and streaking over the surface of the slant. The inoculum was obtained by a slight touch of a straight needle to the slant of Kligler iron agar culture.

Incubation and readings of the results. All inoculated media were incubated at $37 \mathrm{C}$. The typical reactions on DMS agar are clear-cut and readings can be made at $48 \mathrm{~h}$ of incubation.

One set of three tubes containing dulcitol, salicin, and malonate broths, respectively, and another tube containing the DMS agar were used simultaneously in this study to decide which way was easier to work. Our technician found it a significant advantage that the DMS agar was easier and quicker to prepare and inoculate and required less space in the racks.

The results obtained by the three-tube conventional method and the color reactions on the 
DMS agar version at $48 \mathrm{~h}$ of incubation are compared in Table 2. It must be emphasized that discrepancies were not found.

Dulcitol fermentation in DMS agar is denoted by the production of an initial acid butt and slant in a short incubation period. As dulcitol is utilized, the reaction of the medium under aerobic conditions reverts and becomes alkaline since the alkalinization due to bacterial growth is more prominent than acidification due to the fermentation of a small amount of dulcitol. Under anaerobic conditions in the butt, the bacterial growth is not sufficient to cause a reversion of the reaction and the butt remains acid. If malonate is utilized during bacterial growth, the slant of DMS agar becomes alkali, changing from green to blue or deep blue. Finally, salicin fermentation is denoted by a yellow discoloration of the entire medium.

Most Salmonella subgenus I strains ferment

TABLE 1. Differential biochemical characteristics of the Salmonella subgenera

\begin{tabular}{lcccc}
\hline \multirow{2}{*}{ Characteristic } & \multicolumn{5}{c}{ Salmonella subgenera } \\
\cline { 2 - 5 } & I & II & II & IV \\
\hline Dulcitol & + & + & - & - \\
Lactose & - & - & $+/ \mathbf{x}$ & - \\
ONPG $^{b}$ & - & $-/ \mathbf{x}$ & + & - \\
Salicin & - & - & - & + \\
$d$-Tartarate & + & $-/ \mathbf{x}$ & $-/ \mathbf{x}$ & - \\
Mucate & + & + & $\mathbf{d}$ & - \\
Malonate & - & + & + & - \\
Gelatin & - & + & + & + \\
KCN & - & - & - & + \\
\hline
\end{tabular}

${ }^{a} \mathrm{Key}: /=$ or; $\mathrm{x}$, late and irregularly positive; $\mathrm{d}$, different types; + , positive; - , negative.

${ }^{b}$ ONPG, $o$-Nitrophenyl- $\beta$-D-galactopyranoside. dulcitol promptly, turning the color of the butt yellow, while the color of the slant reverts to pale green. Some Salmonella subgenus I strains which do not ferment dulcitol will produce a dark green slant (spontaneous alkalinization due to bacterial growth under aerobic conditions) and a neutral green butt. Salmonella subgenus II strains develop a yellow butt and deep blue slant, but instead of producing a purely yellow color, like subgenus I strains (dulcitol fermenters), they make the butt appear more greenish. The subgenus III strains color the slant to deep blue and the butt remains a neutral green. The subgenus IV strains (those which fement salicin) produce yellow discoloration initially in the butt, and in the entire medium at $48 \mathrm{~h}$ of incubation.

A method of approaching the problems of distribution and the pathogenic role of all $\mathrm{Sal}$ monella subgenera and the problems of mixed Salmonella infections is the screening (by picking and identifying) of a large number of suspicious colonies from the selective plating media. The use of multitest media is especially recommended for preliminary screening of large numbers of suspicious colonies to save time and materials. Since Russel in 1911 introduced his double-sugar medium, there have been a number of modifications of it, as well as the introduction of other composite media aimed mainly at facilitating the biochemical identification of enteric pathogens. The principles governing the use of a multitest medium are: (i) the practical value of the biochemical reactions on which it was based within the group studied, (ii) the ease with which the medium can be prepared and the test performed, and (iii) the test's reliability. The differential mechanism of DMS agar is based on three biochemical reactions, namely dulcitol and salicin fermentation and utilization of

TABLE 2. Results obtained by conventional procedures in comparison with the color reactions in DMS agar

\begin{tabular}{|c|c|c|c|c|c|c|}
\hline \multirow{2}{*}{$\begin{array}{l}\text { Salmonella } \\
\text { subgenera }\end{array}$} & \multirow{2}{*}{$\begin{array}{l}\text { Total } \\
\text { no. of strains }\end{array}$} & \multicolumn{3}{|c|}{$\begin{array}{c}\text { Results of } \\
\text { conventional procedures }\end{array}$} & \multicolumn{2}{|c|}{ DMS agar color reactions $^{a}$} \\
\hline & & $\begin{array}{l}\text { Dulci- } \\
\text { tol }\end{array}$ & $\begin{array}{l}\text { Malo- } \\
\text { nate }\end{array}$ & Salicin & Butt & Slant \\
\hline \multicolumn{7}{|l|}{ Subgenus I } \\
\hline Dulcitol negative & 13 & - & - & - & N. green & N. green \\
\hline Dulcitol positive & 8 & + & - & - & Yellow & P. green \\
\hline Subgenus II & 20 & + & + & - & Y. green & D. blue \\
\hline Subgenus III & 26 & - & + & - & N. green & D. blue \\
\hline \multicolumn{7}{|l|}{ Subgenus IV } \\
\hline Salicin negative & 2 & - & - & - & N. green & N. green \\
\hline Salicin positive & 10 & - & - & + & Yellow & Yellow \\
\hline
\end{tabular}

${ }^{a}$ Key: N. green, neutral green; D. green, deep green; P. green, pale green; D. blue, deep blue; Y. green, yellow green. 
sodium malonate. As a rule, the members of subgenus I (with some exception) and subgenus II (11) ferment dulcitol promptly, whereas those of subgenera III and IV do not. On the other hand the members of subgenera II and III give a positive malonate test, whereas those of subgenera I and IV do not attack sodium malonate at all. Finally, since the above-mentioned dulcitol-negative subgenus I strains can resemble subgenus IV strains, salicin was incorporated in the medium to detect salicin-positive subgenus IV strains. DMS agar combines these reactions in such a manner that each individual subgenus gives a different reaction pattern. By this pattern, subgenera are readily identified. It should be emphasized that DMS agar is intended as a screening test medium and is not meant to replace the full spectrum of biochemical tests required for complete characterization of Salmonella subgenera. Occasionally atypical strains may not be readily identified, or may be incorrectly identified. Such aberrant forms may require extended testing, but the medium nevertheless serves a useful function in providing substantial information which will facilitate eventual recognition of the strains. The DMS agar represents a simple way of reducing the number of tubes which the technician has to handle while performing the routine conventional differentiation procedures. This simplified method would facilitate differentiation of Salmonella subgenera in those laboratories already using conventional procedures. Also, those laboratories which are not able to perform such testing for reasons of time, personnel, or economy might be able to institute a limited but effective screening procedure.

The DMS agar has given results that correspond well with the tests separately performed. Applied as the third step, after Kligler iron agar and Taylor lysine decarboxylase broth in the preliminary screening of a large number of suspicious colonies ("the step-by-step" principle), DMS agar would be very useful to detect the possible presence of Salmonella subgenera other than I.

Finally, it should be emphasized that DMS agar has a minimal nutrient nature, the bacterial growth is not luxuriant on its slant, and it is not suitable as a source of cells for $\mathrm{O}$ group serology.

\section{ACKNOWLEDGMENTS}

I thank The Bulgarian Collection of Type Cultures, Sofia; P. A. M. Guinee, The National Institute of Public Health, Utrecht, The Netherlands, L. LeMinor, Institute Pasteur, Paris; J. Sourek, The Czechoslovak State Collection of Type Cultures; A. B. Peterson and H. N. Spears, The Central Veterinary Laboratory, Weybridge, England; G. H. Snoeyenbos, The University of Massachusetts; and R. Sakazaki, The National Institute of Health, Tokyo, for kindly providing stock cultures.

\section{REPRINT REQUESTS}

Address reprint requests to: Dr. Stefan Ivanov Bonev, Laboratory for Zoonoses, Dargaven Ekarisage, Burgas, Bulgaria.

\section{LITERATURE CITED}

1. Edwards, P. R. 1963. Kauffmann-White schema (modified). Center for Disease Control, Atlanta.

2. Edwards, P. R., M. A. Fife, and W. H. Ewing. 1965. Antigenic schema for the genus Arizona. Center for Disease Control, Atlanta.

3. Ewing, W. H., and M. M. Ball. 1966. The biochemical reactions of members of the genus Salmonella.

4. Ewing W. H., and B. R. Davis. 1970. Media and tests for differentiation of Enterobacteriaceae. Center for Disease Control, Atlanta.

5. Ewing, W. H., B. R. Davis, and R. W. Reawis. 1957. Phenylalanine and malonate media and their use in enteric bacteriology. Public Health Lab. 15:153-167.

6. Kauffmann, F. 1960. The biochemical subdivision of the genus Salmonella. Acta Pathol. Microbiol. Scand. 49: 393-396.

7. Kauffmann, F. 1961. Die Bacteriologie der Salmonella Species. E. Munksgaard, Copenhagen.

8. Kauffmann, F. 1963. Zür Differentialdiagnose der salmonella-Subgenera I, II und III. Acta Pathol. Microbiol. Scand. 58:109-113.

9. Kauffmann, F. 1965. Wietiere Salmonella-species der Subgenera II, III und IV. Acta Pathol. Microbiol. Scand. 64:367-372.

10. Kauffmann, F. 1969. The bacteriology of Enterobacteriaceae, 2nd ed. Munksgaard, Copenhagen.

11. Kauffmann, F. 1972. Zür Differentialdiagnose der Salmonella Subgenera II und III. Zentralbl. Bakteriol. Parasitenk d. Infektionskr. Hyg. Abt. 1 Orig. Reihe A.

12. Leifson, F. 1933. The fermentation of sodium malonate as a means of differentiating Aerobacter and Escherichia. J. Bacteriol 26:329-330.

13. Shaw, G., and P. H. Clarke. 1965. Biochemical differentiation of Proteus and Providencia cultures. J. Gen. Microbiol. 13:155-165.

14. Steel, R. J. 1962. The practice of bacterial identification. Symp. Soc. Gen. Microbiol. 12:405.

15. Stroup, J. R. 1972. Malonate dulcitol lysine iron agar. "A new differential medium for the identification of Salmonella subgenera I-III. JAOAC, Vol. 55. 